\title{
Predictive factors for the presence of tumor cells in bone marrow and peripheral blood in breast cancer patients
}

\author{
M. CABINAKOVA ${ }^{1}$, V. MIKULOVA ${ }^{2}$, K. MALICKOVA ${ }^{2}$, D. VRANA ${ }^{3, *}$, D. PAVLISTA ${ }^{4}$, L. PETRUZELKA $^{1}$, T. ZIMA ${ }^{2}$, P. TESAROVA $^{1}$
}

${ }^{1}$ Department of Oncology, First Faculty of Medicine, Charles University in Prague and General University Hospital, Prague, Czech Republic; ${ }^{2}$ Institute of Medical Biochemistry and Laboratory Diagnostics, First Faculty of Medicine, Charles University in Prague and General University Hospital, Prague, Czech Republic; ${ }^{3}$ Department of Oncology, Faculty of Medicine and Dentistry, Palacky University, Olomouc, Czech Republic; ${ }^{4}$ Department of Obstetrics and Gynecology, First Faculty of Medicine, Charles University in Prague and General University Hospital, Prague, Czech Republic

${ }^{*}$ Correspondence: davvrana@gmail.com

Received March 9, 2014 / Accepted June 11, 2014

Simultaneous detection of disseminated tumor cells (DTCs) and circulating tumor cells (CTCs) was shown to be associated with an especially poor prognosis and increased incidence of disease-related deaths in non-metastatic breast cancer patients. We analyzed the occurance of DTCs and CTCs in patients with primary breast cancer and evaluated the correlation of their presence with other prognostic markers and investigated the changes in DTCs/CTCs number at different time points during treatment.

Blood of 50 patients with primary breast cancer were used for immunomagnetic separation and detection of circulating tumor cells using the commercial available system the AdnaTest Breast Cancer ${ }^{\text {rm }}$ (AdnaGen GmbH, Langenhagen, Germany). Bone marrow aspirates from 50 patients were analyzed for DTCs by immunocytochemistry using the pan-cytokeratin antibody conjugated with FITC (Monoclonal Anti-Cytokeratin antibody F3418, Sigma Aldrich).

DTCs were identified in $30 \%(15 / 50)$ and CTCs in $22 \%(11 / 50)$ of patients. We found that DTC positivity could point to a significantly high risk of larger primary tumor size (p-value 0.011 ) and significantly higher risk of lymph node involvement (p-value 0.002). For CTC positivity, no such relationship was proven. DTCs have shown significantly higher prevalence in ER/PR-negative females and in HER2-positive cases. CTCs were equally prevalent in patients with the presence and absence of standard prognostic and predictive markers such as ER, PR and HER2. We found no correlation between CTCs and DTCs findings ( $\mathrm{r}=-0.097, \mathrm{p}=0.504)$. We used DTCs/CTCs analysis for therapy monitoring in a small group of 29 patients, who underwent neoadjuvant chemotherapy (NACT). We find out no significant correlation between DTCs/CTCs detection and the primary tumor response to NACT. A pathologic complete response (pCR) was achieved by $31 \%(9 / 29)$ of the patients in our study, however, no association was observed between pCR and the detection of DTCs after NACT.

These results support the use of DTCs/CTCs analysis in early breast cancer to generate clinically useful prognostic information. The study of these cells apart from the impact on refining prognosis, has the exciting potential of individualising treatment for women with breast cancer.

Key words: breast cancer, disseminated tumor cells, circulating tumor cells, bone marrow aspiration, prognostic/predictive markers, therapy monitoring

Breast cancer is the most common invasive cancer in women with a incidence in all developed countries, especially northern and western Europe and North America. Time survival rates have been steadily increasing, partly due to earlier diagnosis as a result of mammography screening programs and improving treatment. Despite these advances however, at diagnosis $5 \%$ of patients demonstrate clinically detectable metastases and an additional 30-40\% have occult metastases [1,2] which may lead to disease relapse. Detection of disseminated tumor cells (DTCs) in bone marrow (BM) and circulating tumor cells (CTCs) in peripheral blood (PB) has emerged as one of the hottest fields of cancer research as there is a need for new prognostic/predictive markers that can improve stratification of breast cancer patients. The 
availability of early predictive markers of treatment response could prevent exposure to ineffective therapies as well as unnecessary treatment in patients with refractory disease [3]. The application of DTC and CTC analyses was mentioned for the first time in 2007 in the American Society of Oncology (ASCO) recommendations on tumor markers [4]. Several large studies have shown that the presence of DTCs in BM after adjuvant therapy is a predictor of poor prognosis $[5,6,7]$. Patients with high-risk breast cancer (more than three involved axillary lymph nodes or lymphangio-invasion) receiving standard taxane or anthracycline chemotherapy regimens were monitored by BM analysis before and after adjuvant chemotherapy. The presence of tumor cells after therapy was associated with an extremely poor prognosis and pointed to a heterogeneous response treatment. Despite its proven clinical utility, the collection of BM is problematic and requires invasive procedures that are unpleasant for the patient and inconvenient for the physician. To date, it is not clear whether CTC measurements could replace the examination of BM. It is well known that $25 \%$ of patients with stage I breast cancer will experience systemic relapse. Many prognostic markers have been proposed, but none of them is able to reliably identify this high-risk subgroup of patients. CTCs represent a possible tool: their delivery into the circulatory system is recognized as the first step in the hematogenous metastatic process [8]. Some authors have focused on the association of pathologic characteristics of the primary tumor and the presence of CTCs,

Table 1. Clinicopathologic Features of Patients $(n=50)$

\begin{tabular}{lcc}
\hline Variable & No. of patients & $\%$ \\
\hline Median age (years) & 37 & NA \\
\hline Tumor classification & 24 & 48 \\
T1 & 19 & 38 \\
T2 & 7 & 14 \\
T3/4 & 3 & \\
\hline Tumor grade & 20 & 6 \\
Low & 27 & 40 \\
Intermediate & & 54 \\
High & 44 & \\
\hline Primary tumor histologic type & 2 & 88 \\
Ductal invasive & 4 & 8 \\
Lobular invasive & & \\
Others & 30 & 60 \\
\hline Hormone receptor status & 29 & 58 \\
Estrogen receptor positive & 11 & 22 \\
Progesterone receptor positive & & \\
HER2 positive & 30 & 60 \\
\hline Lymph node status & 18 & 36 \\
Lymph node negative & 2 & 4 \\
Lymph node positive & & \\
Lymph node unknown &
\end{tabular}

NA indicates not applicable

HER2 human epidermal growth factor receptor 2 and some reports have demonstrated an association between HER2 overexpression and the presence of CTCs [9]. Little data are available on evaluating the possible modification of CTC detection in the perioperative period of patients undergoing surgery for operable breast cancer. However, this information may increase our knowledge of the biology of the metastatic process and in particular, about the impact of surgery on the release of cells into the bloodstream. Moreover, detection of CTCs in the blood after resection of the primary tumor and their analysis during the follow up of breast cancer patients could be of clinical value with respect to earlier prediction of recurrence, possibly an advantageous method in comparison to elevations of serum tumor markers. In the present study, we investigated the occurrence of DTCs in bone marrow and CTCs in peripheral blood from patients with non-metastatic breast cancer and we evaluated the correlation of their presence with standard prognostic markers, including tumor size, tumor histologic grade, estrogen receptor (ER) status, progesterone (PR) status, human epidermal growth factor status (HER2 gene amplification) and the status of axillary lymph nodes. We assessed the correlation between DTCs in bone marrow and CTCs in blood, and subsequently, we explored the changes in DTCs/CTCs at different time points during treatment.

\section{Patients and methods}

Patients. The study was conducted at the General University Hospital and First Faculty of Medicine, Charles University in Prague. The recruitment period was between January 2010 and September 2013. The study protocol was approved by the Institutional Ethics Committee. In total, 50 primary breast cancer patients ( $\mathrm{T} 1$ to $\mathrm{T} 4, \mathrm{~N} 0$ to $\mathrm{N} 2, \mathrm{M} 0$ ) were included in the study. Patient tumor characteristics at the time of diagnosis are summarized in Table 1. Metastatic spread was excluded by chest X-ray, liver ultrasound and bone scan. The cut-off used to define hormone receptor positivity was $5 \%$ of stained cells. HER2 status was considered positive if the HerceptTest result was $3+$. In doubtful cases (2+), a fluorescent in situ hybridization was done. All patients provided informed written consent before enrollment into the study. We had two subgroups of patients. In the first subroup, patients were treated initially with neoadjuvant chemotherapy (NACT), followed by surgery and adjuvant treatment. Patients with T2-4 N0-2 were included in this subset of patients. We investigated bone marrow and peripheral blood of 29 patients before NACT and after completion of NACT at the time of surgery. The second subgroup of 21 patients with T1-2 N0-1 underwent primary surgery followed by adjuvant treatment. Bone marrow aspirates and peripheral blood samples were obtained from the patients under general anesthesia at the time of surgery (breast-conserving surgery or breast ablation and axillary clearance). Follow up sampling was performed after 12 months of adjuvant treatment.

Collection of bone marrow. Five $\mathrm{ml}$ of bone marrow was aspirated from sternum under local anaesthesia or under general anesthesia at the time of surgery to the BD Vacutainer ${ }^{\circ}$ 
$\mathrm{K}_{3}$ EDTA tubes (Becton Dickonson Diagnostics, USA). Bone marrow was obtained as mentioned in the previous paragraph.

Collection of peripheral blood. Seven $\mathrm{ml}$ of peripheral blood was drawn either into BD Vacutainer ${ }^{\oplus} \mathrm{K}_{3}$ EDTA tubes (Becton Dickonson Diagnostics, USA) for immediate processing or into AdnaCollect tubes (AdnaGen $\mathrm{GmbH}$, Langenhagen, Germany) for processing within $24 \mathrm{~h}$ after collection. Peripheral blood samples were collected at the same time as bone marrow samples.

Processing of bone marrow samples. Aspirate of bone marrow was poured into a $50 \mathrm{~mL}$ tube and filled up with Hanks solution to a volume of $20 \mathrm{~mL}$ and centrifuged for 10 minutes at $168 \mathrm{xg}$. The upper layer was discarded and the pellet was resuspended. This cell suspension was used for separation by density gradient centrifugation to obtain the fraction of mononucleated cells using Leucosep ${ }^{\text {min }}$ tubes (Greiner Bio-One GmbH, Germany). Density gradient centrifugation was performed according to the manufacturer's instructions. The interphase layer containing mononucleated cells was washed with $10 \mathrm{~mL}$ of phosphate-buffered saline (PBS) and then centrifuged for 10 minutes at $250 \mathrm{x}$ g. This step was repeated twice, then the cell pellet was resuspended with $5 \mathrm{ml}$ of PBS. The cellularity was counted and cell suspension as a concentration of $1 \times 10^{6} / 900 \mathrm{ul}$ cells was adjusted. $300 \mathrm{ul}$ of cell suspension were pipetted onto each spot area on poly-L-lysine coated glass slides (Poly-Prep Slides, Sigma-Aldrich). The slides were incubated in a moist chamber for 30 minutes at room temperature and left at room temperature to dry completely.

Immunofluorescent staining of disseminated tumor cells. Slides with air-dried cell suspension were fixed with $3.7 \%$ solution of $\mathrm{p}$-formaldehyde for 10 minutes at room temperature. They were washed three times with PBS and then $0,5 \%$ Tween 20 solution was added and the slides were incubated for 15 minutes at room temperature. They were washed three times with PBS and antibody solution was applied. The antibody solution consisted of dilution buffer (Couating Stabilizer and Blocking Buffer, Sigma Aldrich) and pan-cytokeratin antibody conjugated with FITC (Monoclonal Anti-Cytokeratin antibody F3418, Sigma Aldrich). The antibody solution was incubated for $12 \mathrm{~h}$ at room temperature in the dark. The slides were then washed with PBS and mounted with mounting media ProLong ${ }^{\oplus}$ Gold Antifade Reagent with DAPI (Molecular Probes ${ }^{\circ}$, Life Technologies). The slides were observed using fluorescent microscope Olympus BX51.

Processing of peripheral blood samples and detection of circulating tumor cells. Peripheral blood samples were used for immunomagnetic separation and detection of circulating tumor cells using the commercial available system the AdnaTest Breast Cancer ${ }^{\mathrm{Tm}}$ (AdnaGen $\mathrm{GmbH}$, Langenhagen, Germany). The peripheral blood was processed according to the manufacturer's instruction. Epithelial cells were incubated with ready-to-use mixture of antibody (against GA733-2 and MUC1). The labelled cells were extracted by a magnetic par- ticle concentrator and further lyzed. The cell lysate was used for isolation of mRNA using Dynabeads mRNA DIRECT Microkit (Dynal Biotech GmbH, Hamburg, Germany). mRNA was used for reverse transcription which resulted in cDNA. cDNA was used as the template for tumor cell detection and characterization by multiplex PCR (polymerase chain reaction) and PCR fragment of three tumor associated antigens and one control gene were generated. The primers generated fragments of the following sizes: GA 733-2, $395 \mathrm{bp}$; MUC1, 293 bp; HER2, 270 bp and actin 114bp. Visualization of PCR fragments was processed with a 2100 Bioanalyzer using DNA 1000 Labchip (Agilent Technologies, Santa Clara, CA, USA) and the Expert Software Package (Agilent Technologies, version B.02.08).

Statistical analysis. Prior to running the experiments, the required sample size was calculated by the freeware Epi $\mathrm{Info}^{\mathrm{TM}} 6.04$ from the Centers for Disease Control and Prevention (USA). The statistical software STATISTICA CZ version 12.0 (StatSoft Inc, USA) was used for further statistical tests. Standard descriptive statistics were used to describe frequency distributions for categorical data and medians and interquartile ranges for other variables. Summary data are expressed as medians \{interquartile range\} or percentage. Fisher's exact test was used for the calculations of exact probability value for the relationship between two dichotomous variables. Different groups were compared using a two-tailed Kruskal-Wallis non-parametric test. The Spearman rank test was used for correlations between variables. A two-tailed $p$-value $\leq 0.05$ was considered statistically significant.

\section{Results}

Clinicopathologic characteristics of the patients. A total of 50 female patients, median age 37 years (interquartile range $33.75-40.50$ years) were included in the study. Twenty four out of $50(48 \%)$ patients had T1 tumors, 19 patients (38\%) had T2 tumors and the rest were characterized by T3/T4 tumors. Before the surgery, in 18 patients ( $36 \%$ ) lymph node involvement was detected (N1 or N2 nodal status). Most primary tumors were ductal invasive (88\%). The primary breast tumor was categorized as low grade in 3 patients, intermediate grade in 20 patients, and high grade in 27 patients. In tumor biopsies, HER2 expression was positive in 11/50 of females (22\%), ER positivity in 30/50 (60 \%) cases and PR positivity in 29 out of 50 patients (58\%). Triple negativity (ER negative/PR negative/ HER2 negative) was found in 28\% (14/50). Clinical data are presented in detail in Table 1.

Occurrence of CTCs and DTCs in relation to the TNM characteristics of the disease. Initially, CTCs were detected in 11 of 50 patients $(22 \%)$. Distribution of CTCs in relation to TNM classification is shown in Table 2. Initially, DTCs were found in 15 out of 50 (30\%) patients, see Table 3 . Thus, only DTCs showed significantly higher positivity in patients with the advanced disease staging. This could be applied for the primary tumor size (T category) and lymph node involvement 
Table 2. CTCs detection in relation to TNM classification

\begin{tabular}{|c|c|c|c|c|c|c|c|c|}
\hline & & \multicolumn{2}{|c|}{$\begin{array}{l}\text { All patients } \\
\mathrm{n}=50\end{array}$} & \multicolumn{2}{|c|}{$\begin{array}{l}\text { CTC positive patients } \\
\qquad \mathrm{n}=11\end{array}$} & \multicolumn{2}{|c|}{$\begin{array}{l}\text { CTC negative patients } \\
\qquad \mathrm{n}=39\end{array}$} & \multirow[t]{2}{*}{$\mathrm{p}$-value } \\
\hline & & $\mathrm{n}$ & $\%$ & $\mathrm{~N}$ & $\%$ & $\mathrm{n}$ & $\%$ & \\
\hline \multirow[t]{3}{*}{ Tumor size } & $\mathrm{T} 1$ & 24 & 48 & 5 & 45.5 & 19 & 48.7 & \\
\hline & $\mathrm{T} 2$ & 19 & 38 & 4 & 36.4 & 15 & 38.5 & 0.418 \\
\hline & $\mathrm{T} 3 / 4$ & 7 & 14 & 2 & 18.2 & 5 & 12.8 & NS \\
\hline \multirow[t]{4}{*}{ Lymph node status } & N0 & 30 & 60 & 7 & 63.6 & 23 & 59.0 & \multirow{4}{*}{$\begin{array}{c}0.304 \\
\text { NS }\end{array}$} \\
\hline & N1 & 17 & 34 & 4 & 36.4 & 13 & 33.3 & \\
\hline & $\mathrm{N} 2$ & 1 & 2 & 0 & 0 & 1 & 2.6 & \\
\hline & $\mathrm{Nx}$ & 2 & 4 & 0 & 0 & 2 & 5.1 & \\
\hline
\end{tabular}

Table 3. DTCs detection in relation to TNM classification

\begin{tabular}{|c|c|c|c|c|c|c|c|c|}
\hline & & \multicolumn{2}{|c|}{$\begin{array}{l}\text { All patients } \\
\mathrm{n}=50\end{array}$} & \multicolumn{2}{|c|}{$\begin{array}{l}\text { DTC positive patients } \\
\qquad \mathrm{n}=15\end{array}$} & \multicolumn{2}{|c|}{$\begin{array}{l}\text { DTC negative patients } \\
\qquad \mathrm{n}=35\end{array}$} & \multirow[t]{2}{*}{$\mathrm{p}$-value } \\
\hline & & $\mathrm{n}$ & $\%$ & $\mathrm{n}$ & $\%$ & $\mathrm{n}$ & $\%$ & \\
\hline \multirow[t]{3}{*}{ Tumor size } & $\mathrm{T} 1$ & 24 & 48 & 4 & 26.7 & 20 & 58.3 & \\
\hline & $\mathrm{T} 2$ & 19 & 38 & 8 & 53.3 & 11 & 30.6 & $0.011^{\star}$ \\
\hline & $\mathrm{T} 3 / 4$ & 7 & 14 & 3 & 20.0 & 4 & 11.1 & \\
\hline \multirow[t]{4}{*}{ Lymph node status } & No & 30 & 60 & 7 & 46.7 & 23 & 65.7 & \\
\hline & N1 & 17 & 34 & 6 & 40.0 & 11 & 31.4 & $0.002^{\star *}$ \\
\hline & $\mathrm{N} 2$ & 1 & 2 & 1 & 6.7 & 0 & 0 & \\
\hline & $\mathrm{Nx}$ & 2 & 4 & 1 & 6.7 & 1 & 2,9 & \\
\hline
\end{tabular}

NS - non-significant; ${ }^{*}-p<0.05 ;{ }^{* *}-p<0.01$.

(N category). We found no correlation between CTCs and DTCs findings $(\mathrm{r}=-0.097, \mathrm{p}=0.504)$.

Occurrence of CTCs and DTCs in relation to the hormonal receptor and HER2. CTCs were detected in 23\% patients with ER positive disease versus $20 \%$ of patients with ER negative disease, in $21 \%$ of patients with PR positive disease versus $24 \%$ patients with PR negative disease, and in $18 \%$ patients with HER 2 positive disease versus $23 \%$ of patients with HER2 negative disease. DTCs were observed in $20 \%$ patients with ER positive disease versus $45 \%$ of patients with ER negative disease, in $24 \%$ of patients with PR positive disease versus $38 \%$ patients with PR negative disease, and in 36\% patients with HER 2 positive disease versus $28 \%$ of patients with HER 2 negative disease. In summary, CTCs were equally prevalent in patients regardless of the presence or absence of standard prognostic and predictive markers such as ER, PR and HER2. In contrast, DTCs showed significantly higher prevalence in ER/PR-negative females. In HER2-positive cases, DTC presence was significantly more frequent. Figure1 illustrates CTCs and DTCs in primary tumors based on their hormonal receptor and HER 2 status proven by biopsy.

For a binary outcome that measures (1) T1 versus $\geq \mathrm{T} 2$ size of tumor, (2) N0 versus $\geq$ N1 lymph nodes involvement, (3) hormone receptor status - ER positive versus ER negative, PR positive versus PR negative, and (4) histological grade 1 versus grade 2-3, a survey logistic regression model was used to analyze the relationship between the binary dependent variable and two analyses: CTCs and DTCs. DTC positivity could point to a significantly high risk of larger primary tumor size and significantly higher risk of lymph node involvement. For CTC positivity, no such relationship was proven, see Table 4 .

Correlation between the presence of CTCs in the blood and DTCs in bone marrow. The detection of both CTCs and DTCs was initially performed in 50 patients in this study. Two of 50 patients demonstrated the presence of both CTCs and DTCs. The clinicopathologic features of these two patients did not differ significantly from the features of patients who had either CTCs or DTCs or from the features of patients who were negative for minimal residual disease. We detected CTCs alone in 9 of 50 patients and DTCs alone in 13 of 50 patients. Basically, there was no correlation between the occurrence of CTCs and the occurrence of DTCs in this study $(p=0.054)$. Twenty six of 50 patients showed no evidence of CTCs or DTCs. The clinicopathologic features of these twenty five patients did not differ significantly from the features of patients with minimal residual disease. To obtain information on the frequency of CTCs and DTCs during the course of treatment, serial examinations were done before and after treatment in randomly chosen patients (i.e. the selection was 


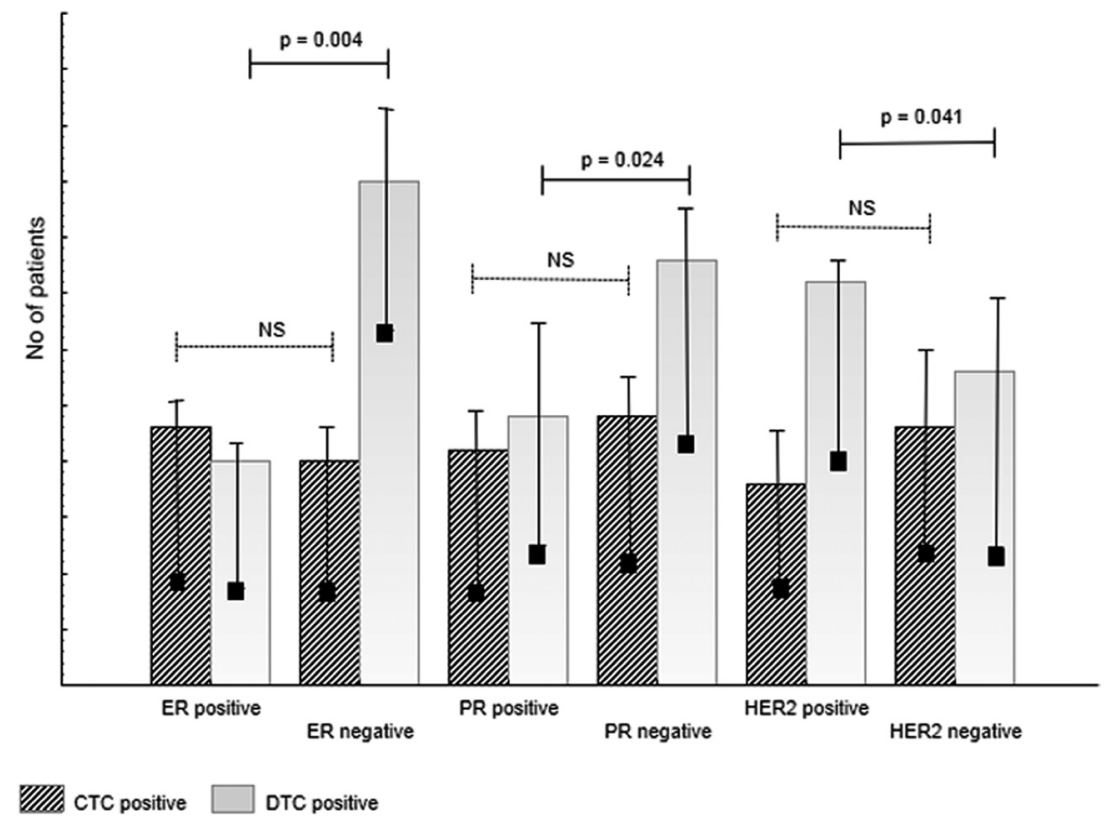

Figure 1. CTCs and DTCs according to the hormonal receptor and HER2 status of the breast tumor $E R$, estrogen receptors; PR, progesteron receptors; HER2, human epidermal growth factor receptors; CTC, circulating tumor cells; DTC, disseminated tumor cells; NS, non-significant; Black squares represent medians.

not based on baseline test results). In 32 patients, repeated CTC measurements were done, and in 21 of these, DTCs were repeatedly measured.

CTCs during treatment. Of 32 females with repeated CTC detection, there were 22 with initially negative CTC examination and 10 patients with positive CTCs. Three of the initially negative patients (13.6\%) became positive in control sampling. During therapy, CTCs disappeared in 9/10 (90\%) patients who had initially detectable CTCs in peripheral blood samples, see Figure 2.

DTCs during treatment. Of 21 repeatedly examined patients, there were 12 DTC-negative and 9 DTC-positive females. $41,7 \%(5 / 12)$ of initially negative patients became positive in control sampling. Only two patients with DTC positivity in the first sample remained positive, most of these ( 7 out of 9 ) became negativity at follow up examination, see Figure 2.

DTCs/CTCs changes in adjuvant and neoadjuvant subgroup of patients. In the first group of patients, we analyzed DTCs in bone marrow and CTCs in blood before and after neoadjuvant chemotherapy. A total of 29/50 were treated with neoadjuvant chemotherapy. Initially, DTCs were found in 11 out of $29(38 \%)$ patients and CTCs in 5 out of $29(17 \%)$ patients. Control sampling of DTCs/CTCs was done after neoadjuvant chemotherapy. We identified DTCs in $37 \%$ of patients after the completion of NACT. Only two patients with DTC positivity before NACT remained positive after completion of NACT. Four of 18 patients (22\%) initially DTC negative became DTC positive in control sampling. Repeated analysis of blood revealed the occurrence of CTCs in 1 of
5 patients that were initially positive, whereas CTCs were detected in three initially negative patients, see Figure 3.

Of these 29 patients, 9 (31\%) attained pathologic complete response (pCR). Pathologic complete response correlated with high tumor grade (8/9 had grade 3 ) and triple-negativity (ER

Table 4. Stepwise multivariate modeling results of pre-treatment CTC and DTC positivity.

\begin{tabular}{|c|c|c|c|}
\hline & & CTC positivity & DTC positivity \\
\hline Size of the tumor & OR & 1.24 & 2.317 \\
\hline \multirow{2}{*}{$\mathrm{T} 1$ versus $\geq \mathrm{T} 2$} & $95 \% \mathrm{CI}$ & $0.51-5.71$ & $0.035-4.667$ \\
\hline & $\mathrm{p}$-value & $0.102, \mathrm{NS}$ & $0.0249^{*}$ \\
\hline Lymph nodes status & $\mathrm{OR}$ & 1.65 & 3.260 \\
\hline \multirow[t]{2}{*}{ No versus $\geq$ N1 } & $95 \% \mathrm{CI}$ & $0.85-12.90$ & $1.059-8.374$ \\
\hline & $\mathrm{p}$-value & $0.093, \mathrm{NS}$ & $0.0047^{\star *}$ \\
\hline Hormone receptor status & OR & 0.95 & 1.984 \\
\hline \multirow[t]{2}{*}{$\mathbf{E R}+$ versus $\mathbf{E R}-$} & $95 \% \mathrm{CI}$ & $0.42-3.24$ & $0.98-4.26$ \\
\hline & $\mathrm{p}$-value & $0.345, \mathrm{NS}$ & $0.0371^{\star}$ \\
\hline \multirow{3}{*}{$\begin{array}{l}\text { Hormone receptor status } \\
\mathbf{P R}+\text { versus } \mathbf{P R} \text { - }\end{array}$} & OR & 0.89 & 1.879 \\
\hline & $95 \% \mathrm{CI}$ & $0.32-2.99$ & $0.09-3.54$ \\
\hline & $\mathrm{p}$-value & $0.410, \mathrm{NS}$ & $0.0405^{\star}$ \\
\hline \multirow{3}{*}{$\begin{array}{l}\text { Tumor grade } \\
\text { I versus II, III }\end{array}$} & OR & 1.09 & 1.04 \\
\hline & $95 \% \mathrm{CI}$ & $0.58-4.27$ & $0.047-2.98$ \\
\hline & $\mathrm{p}$-value & 0.108, NS & $0.057^{*}$ \\
\hline
\end{tabular}

Odds ratios (ORs) and $95 \%$ confidence intervals (CIs) are shown for primary tumor characteristics.

NS - non-significant; ${ }^{*}-p<0.05 ;{ }^{*}-p<0.01$. 


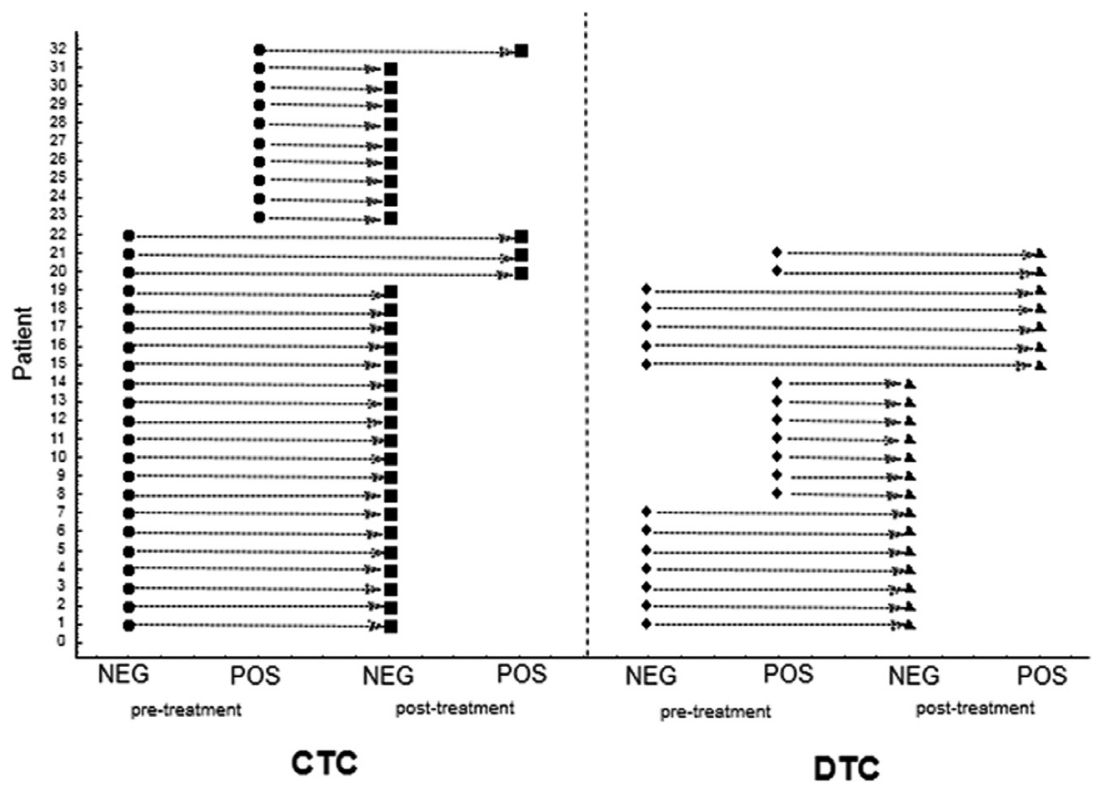

Figure 2. Association of pre-treatment and post-treatment findings

$N E G$ - negative finding; POS - positive finding; CTC - circulating tumor cells; DTC - disseminated tumor cells.

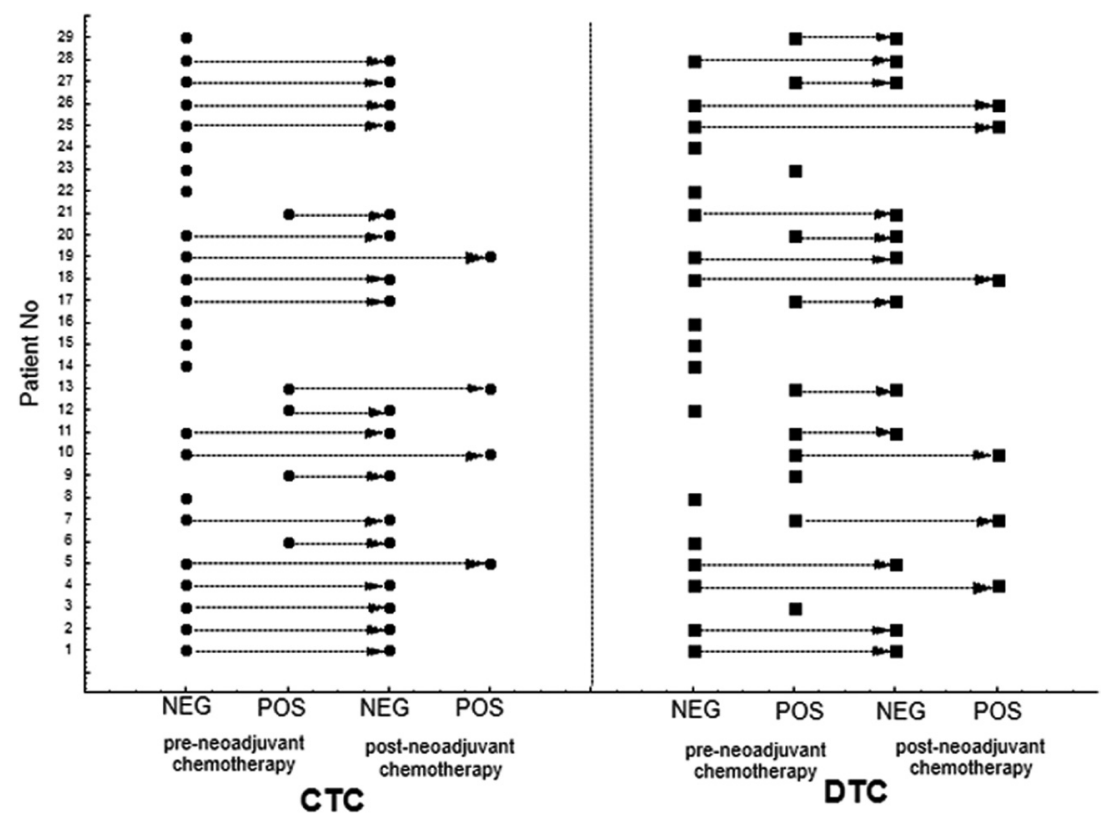

Figure 3. CTCs and DTCs changes in neoadjuvant subgroup of patients

$N E G$ - negative finding; POS - positive finding; CTC - circulating tumor cells; DTC - disseminated tumor cells.

negative/PR negative/HER2 negative) 8 of 9 patients. The presence of DTCs and CTCs was not associated with tumor response to therapy. However, this finding was not statistical significant. In the second group, all patients received adjuvant systemic therapy after initial surgery. In 4 of 21 patients (19\%) DTCs were found in the bone marrow at the time of primary surgery. CTCs positivity was detected in 6 of 21 patients (29\%) at the time of primary surgery. Control analysis of bone marrow and blood were done 12 months after adjuvant treatment. So far, we have not examined all patients undergoing adjuvant therapy.

DTCs/CTCs in pre- and postmenopausal patients. In our cohort, only 4 of 50 (8\%) females were post-menopausal. There 
were not any differences in DTCs/CTCs occurence in these two subgroups of patients, see Table 5 . However, error resulting from the small cohort size must be taken into consideration.

\section{Discussion}

In this study, we investigated disseminated tumor cells in bone marrow and circulating tumor cells in blood in $50 \mathrm{pa}-$ tients with non-metastatic breast cancer. We found that DTCs determined by imunocytochemistry (ICC) can be detected in bone marrow of approximately $30 \%$ patients with breast cancer without distant metastasis. In fact, the detection rate of DTCs in BM from non-metastatic breast cancer patients has been reported to be in the range from $0 \%$ [10] to $100 \%$ [11], and this illustrates the variability of results obtained using different techniques or marker genes. In a large (4703 cases) study of stages I-III breast cancer patients, the incidence of DTCs in BM detected by immunocytochemistry was 30,6\% [12]. Today, in general, there are 2 different methods for screening BM aspirates for DTCs, namely cytologic/cytometric (antibody-based) and molecular approaches [13,14,15]. Of the cytologic methods that allow isolation and enumeration of individual cells, immunocytochemistry is the most widely used [14]. The main advantage of cytologic methods is the opportunity to combine immunostaining with the morphology of the cells so that both cell size and shape as well as the nucleusplasma relation can be estimated and invalid expression of the protein of interest in BM cells can be excluded as far as possible. Besides immunocytochemical methods, very sensitive nucleic acid-based techniques now enable the detection of DTCs at the single cell level. The main advantage of these methods is the nearly unlimited availability of primers for almost every gene of interest. Although numerous genetic alterations have been described in breast cancer cells, the heterogeneity is enormous, so that at present no universally applicable DNA marker exists for the primary screening of a wide range of DTCs $[13,14]$. When we looked at pathological data, we found that DTC positivity could point to a significantly high risk of larger primary tumor size and significantly higher risk of lymph node involvement. DTCs have shown significantly higher prevalence in ER/PR-negative females and in HER2-positive cases. These data are in accordance with a studies by Braun et al. [12] and Wiedswang et al.
[16], who confirmed that patients with bone marrow micrometastasis had larger tumors and tumors with a higher histologic grade and more often had lymph-node metastases and hormone receptor-negative tumors $(\mathrm{p}<0.001$ for all variables). On the other hand, some studies have reported no association between DTC status and tumor stage, node positivity, hormonal status or HER2 expression $[17,18,19]$. Using the AdnaTestBreastCancer system, our CTCs positivity rate was $22 \%$ in primary breast cancer. Detection rates reported by other researchers using different approaches range from $9 \%$ to $50 \%$ depending on the clinical stages included $[20,21,22,23,24]$. There is still currently an ongoing debate whether the RT-PCR (real time polymerase chain reaction) based approach (for example, the AdnaTestBreastCancer ${ }^{\mathrm{TM}}$ ) or the antibody-based approach (for example, the Cell-Search ${ }^{\text {tw }}$ system) is superior in a clinical setting to monitor therapy response and to predict prognosis. False positive results can be obtained using both the molecular approach and the antibody-based assay since only epithelial but not unique breast cancer specific markers are available for identification of breast cancer tumor cells. Until now, few studies have compared both techniques $[25,26]$. When we looked at pathological data, we found no associations between CTCs positivity and T status, node involment, estrogen and progesterone receptor expression, HER2 status. This is consistent with the observation made by Krishnamurthy et al. 2010, who detected CTCs by the CellSearch assay in 92 patients with early stage breast cancer. CTCs occurred in 13 of 43 patients (30\%) with T1 tumors and in 12 of 38 patients (32\%) with T2 tumors. CTCs were equally prevalent in patients regardless of presence or absence of standard prognostic and predictive markers. There was no statistically significant difference between the occurrence of CTCs and the number of lymph nodes involved with metastatic disease or between the presences of micrometastasis versus macrometastasis in the lymph nodes. For this reason, there was no correlation between the detection of CTCs and pathologic characteristics, including tumor histologic grade, ER status, PR status, HER2 positivity, and metastasis to axillary lymph nodes [19]. In contrast to the previous findings of Krishnamurthy and our findings, Fehm et al. evaluated CTCs in blood of 431 primary breast cancer patients and showed that the presence of CTCs significantly correlated with positive nodal status $(\mathrm{p}=0.04)$, negative ER

Table 5. Initial DTCs/CTCs findings in pre- and postmenopausal patients

\begin{tabular}{llccc}
\hline & & premenopausal patients, & postmenopausal patients, \\
$\mathbf{n}=\mathbf{4 6}$ & $\mathbf{4}$ & p-value \\
& & $36(78 \%)$ & $3(75 \%)$ & $0.674, \mathrm{NS}$ \\
& negative, $\mathrm{n}(\%)$ & $10(22 \%)$ & $1(25 \%)$ & \\
positive, $\mathrm{n}(\%)$ & & & $0.508, \mathrm{NS}$ \\
& & $31(67 \%)$ & $4(100 \%)$ & 0 \\
\hline
\end{tabular}

NS - non-significant 
$(\mathrm{p}=0.05)$ and negative $\mathrm{PR}(\mathrm{p}=0.01)$, respectively. The highest CTC positivity rate was obtained in triple-negative patients followed by those with ER-positive and/or PR-positive tumors ( $30 \%$ vs. $13 \%, \mathrm{p}=0.01)$. No CTCs could be detected in the HER2-positive subtype group [27]. In our study, both CTCs in peripheral blood and DTCs in bone marrow occurred simultaneously in only $2 / 50(4 \%)$ of patients with primary breast cancer. The clinicopathologic characteristics of these patients did not differ significantly from the characteristics of patients who demonstrated either CTCs or DTCs alone or from those of patients who were entirely negative for minimal residual disease. The lack of correlation between CTCs and DTCs and either CTCs with standard prognostic and predictive markers in our study raises the possibility of independent modes of dissemination to the different homing sites. The median follow-up for our study was too short, and hence, we did not attempt to assess survival data related to CTCs and DTCs in the current report. However, we plan to perform and report survival analyses once we have longer follow-up. Our results are not in line with Pierga et al. [20], who found a correlation between the occurrence of disseminated tumor cells in bone marrow and circulating tumor cells in patients with primary and metastatic breast cancer. However, they observed no complete concordance between the presence of tumor cells in blood and bone marrow. This might reflect the fact that blood is only a temporary compartment for disseminated cells. The halflife of circulating tumor cells may be short [28] and not all circulating tumor cells may settle in distant organs such as the bone marrow. Taken together, we recommend the measurement of both circulating tumor cells and disseminated cancer cells in bone marrow in the context of clinical studies in M0 patients in order to obtain more information on the added clinical value of circulating tumor cell measurements. We used DTCs/CTCs analysis for therapy monitoring in a small group of 29 patients, who underwent neoadjuvant chemotherapy. We found no significant correlation between DTCs/CTCs detection and the primary tumor response to NACT. We also observed the occurrence of CTCs in patients who were initially negative for CTCs, suggesting that CTCs might be released from distant organs into the circulation [29]. However, this change might also be due to false-negative findings in the initial analyses or a short transit time of CTCs in the circulation. On the other hand, patients with initially detectable CTCs rendered into a negative status, which may suggest a cytotoxic effect of chemotherapy on CTCs in a subset of patients. Also, the switch from DTC negativity to DTC positivity can be explained by the presence of low number of therapy-resistant DTCs (either below or above the detection limit), which will be detected as persistant DTCs at follow-up. Previous findings suggest that DTCs/CTCs are relatively resistant to chemotherapy, probably due to their low proliferative potential $[6,30,31]$. The vast majority of DTCs in BM and CTCs in blood appear to persist in a nonproliferating state which was shown by Ki-67 negativity [21]. Furthermore, only half of the breast cancer patients with DTCs relapse, whereas the other half remains tumor free over a 10-year follow-up period [12]. On the other hand, this dormant state of DTCs/ CTCs might also be the cause for the lack of effect of adjuvant chemotherapy on the elimination of these cells in high-risk breast cancer patients [6]. In order to escape from the dormant state into the dynamic phase of metastasis formation, dormancy has to be disturbed probably by both genetic and epigenetic changes in the DTCs/CTCs as well as in the surrounding microenvironment or premetastatic niche $[32,33]$. However, conditions and timing of outgrowth of dormant tumor cells are not known to date. Our results are in agreement with published reports describing no correlation of DTCs/ CTCs persistence with treatment response $[26,34,35]$. In contrast, Hayes and colleagues indicated that CTCs in peripheral blood of metastatic breast cancer patients at any time during therapy directly reflect the patient's response, or lack of response, respectively, to therapy [36] and are therefore superior or additive to conventional imaging methods $[37,38]$. A pathologic complete response is recognized as an early measure of both local and systemic minimal residual disease after NACT and predicts improved outcome in most patients. A pCR was achieved by $31 \%$ of the patients in our study, however, no association was found between pCR and the detection of DTCs after NACT. Becker et al., in a series of 120 patients undergoing primary systemic therapy, also reported that bone marrow disseminated tumor cells were not completely eradicated in patients with complete pathologic response [30]. In another series of 154 patients, viable disseminated tumor cells were still present in the bone marrow of 10 of 24 patients with pathologic complete response [39]. Pierga et al. investigated 118 patients with locally advanced breast cancer and found that persistence of CTCs at the end of neoadjuvant chemotherapy did not correlate with treatment response but was an independent prognostic factor for early relapse [34]. Pathologic complete response of patients was significantly associated with high tumor grade and triple negativity. This result is in line with the GeparQuattro study. The latter focused on detection and characterization of CTCs before and after neoadjuvant therapy in the peripheral blood of patients with breast cancer. Twenty (15.0\%) initially CTCpositive cases were CTC-negative after NACT, whereas 11 (8.3\%) cases were CTC-positive after NACT, although no CTCs could be found before NACT. CTCs detection did not correlate with primary tumor characteristics. Further, there was no association between tumor response to NACT and CTCs detection [40].

\section{Conclusion}

This study has some limitations. First, it includes a relatively small number of patients, and for some patients, control sampling was not available as a result of a missing sample drawing or unsuccessful collection.

Second, the follow-up period is still too short to permit any conclusions to be drawn regarding the prognostic and 
predictive impact of DTCs/CTCs in the different type of treatment, and we have to wait for a longer time of observation. However, we think that it is important to underline on the basis of previous clinical trials that DTCs/CTCs detection generate prognostic information that would be useful in a clinical setting. Analysis of the fate of DTCs/CTCs during and after treatment can provide information on the presence and load of minimal residual disease at distant sites and indicate the need for optimized treatment. Further molecular characterization of DTCs/CTCs can be helpful in improving and individualizing treatment strategies in breast cancer patients. In conclusion, the continuous progress of basic research towards better understanding of the molecular mechanisms leading to metastasis in combination with the molecular characterization of DTCs/CTCs at the single-cell level holds great promise for successful individualised treatment of breast cancer patients in the near future.

Acknowledgements: This work has been supported by Grant Agency of Charles University no. 59410, by PRVOUK-P-27/LF1/1, by RVO-VFN 64165/2012 and SVV 266515.

\section{References}

1] CLARE SE, SENER SF, WILKENS W, GOLDSCHMIDT R, MERKEL D et al. Prognostic significance of occult lymph node metastases in node-negative breast cancer. Ann Surg Oncol 1997; 4: 447-451. http://dx.doi.org/10.1007/ BF02303667

[2] BRAUN S, PANTEL K, MULLER P, JANNI W, HEPP F et al. Cytokeratin-positive cells in the bone marrow and survival of patients with stage I, II, or III breast cancer. N Engl J Med 2000; 342: 525-533. http://dx.doi.org/10.1056/ NEJM200002243420801

[3] SANCHEZ-MUNOZ A, PEREZ-RUIZ E, JIMENEZ B, RIBELLES N, MARQUEZ A et al. Targeted therapy of metastatic breast cancer. Clin Transl Oncol 2009; 11: 643-650. http://dx.doi.org/10.1007/s12094-009-0419-6

[4] HARRIS L, FRITSCHE H, MENNEL R, NORTON L, RAVDIN P et al. American Society of Clinical Oncology 2007 update of recommendations for the use of tumor markers in breast cancer. J. Clin. Oncol 2007; 25: 5287-5312. http:// dx.doi.org/10.1200/JCO.2007.14.2364

[5] WIEDSWANG G, BORGEN E, KARESEN R, QVIST H, JANBU J et al. Isolated tumor cells in bone marrow three years after diagnosis in diseasefree breast cancer patients predict unfavorable clinical outcome. Clin Cancer Res 2004; 10: 5342-5348. http://dx.doi.org/10.1158/1078-0432.CCR04-0245

[6 BRAUN S, KENTENICH C, JANNI W, HEPP F, DE WAAL J et al. Lack of effect of adjuvant chemotherapy on the elimination of single dormant tumor cells in bone marrow of high-risk breast cancer patients. J Clin Oncol 2000; 18: 80-86.

[7 JANNI W, RACK B, SCHINDLBECK C, STROBL B, RJOSK $\mathrm{D}$ et al. The persistence of isolated tumor cells in bone marrow from patients with breast carcinoma predicts an increased risk for recurrence. Cancer 2005; 103: 884-891. http://dx.doi. org/10.1002/cncr.20834

[8] FIDLER IJ. The pathogenesis of cancer metastasis: the ,'seed and soil" hypothesis revisited. Nat Rev Cancer 2003; 3: 453-8. http://dx.doi.org/10.1038/nrc1098

[9] LANG JE, MOSALPURIA K, CRISTOFANILLI M, KRISHNAMURTHY S, REUBEN J et al. HER2 status predicts the presence of circulating tumor cells in patients with operable breast cancer. Breast Cancer Res Treat 2009; 113: 501-7. http://dx.doi.org/10.1007/s10549-008-9951-2

[10] FETSCH PA, COWAN KH, WENG DE, FREIFIELD A, FILIE AC et al. Detection of circulating tumor cells and micrometastases in stage II, III and IV breast cancer patients utilizing cytology and immunohistochemistry. Diagnostic Cytopatholgy 2000; 22: 323-328. http://dx.doi.org/10.1002/ (SICI) 1097-0339(200005)22:5<323::AID-DC13>3.0.CO;2-L

[11] SLADE MJ, SINGH A, SMITH BM, TRIPURANENI G, HALL E et al. Persistence of bone marrow micrometastases in patients receiving adjuvant therapy for breast cancer: results at 4 years. International Journal of Cancer 2005; 114: 94-100. http://dx.doi.org/10.1002/ijc.20655

[12] BRAUN S, VOGL FD, NAUME B, JANNI W, OSBORNE MP et al. A pooled analysis of bone marrow micrometastasis in breast cancer. N Engl J Med 2005; 353: 793-802. http://dx.doi. org/10.1056/NEJMoa050434

[13] ALIX-PANABIERES C, MULLER V, PANTEL K. Current status in human breast cancer micrometastasis. Curr Opin Oncol 2007; 19: 558-563. http://dx.doi.org/10.1097/ CCO.0b013e3282f0ad79

[14] LACROIX M. Significance, detection and markers of disseminated breast cancer cells. Endocr Relat Cancer 2006; 13: 1033-1067. http://dx.doi.org/10.1677/ERC-06-0001

[15] WOLFLE U, MULLER V, PANTEL K. Disseminated tumor cells in breast cancer: detection, characterization and clinical relevance. Future Oncol 2006; 2: 553-561. http://dx.doi. org/10.2217/14796694.2.4.553

[16] WIEDSWANG G, BORGEN E, KÅRESEN R, KVALHEIM G, NESLAND JM et al. Detection of isolated tumor cells in bone marrow is an independent prognostic factor in breast cancer. Journal of Clinical Oncology 2003; 21: 3469-3478. http://dx.doi.org/10.1200/JCO.2003.02.009

[17] MATHIESEN RR, BORGEN E, RENOLEN A, LØKKEVIK E, NESLAND JM et al. Persistence of disseminated tumor cells after neoadjuvant treatment for locally advanced breast cancer predicts poor survival. Breast Cancer Research 2012; 14.4:R117.

[18] HALL C, KRISHNAMURTHY S, LODHI A, BHATTACHARYYA A, ANDERSON A et al. Disseminated tumor cells predict survival after neoadjuvant therapy in primary breast cancer. Cancer 2011; 118: 342-348. http://dx.doi.org/10.1002/ cncr.26202

[19] KRISHNAMURTHY S, CRISTOFANILLI M, SINGH B, REUBEN J, GAO H et al. Detection of minimal residual disease in blood and bone marrow in early stage breast cancer. Cancer 2010; 116: 3330-3337. http://dx.doi.org/10.1002/cncr.25145

[20] PIERGA J-Y, BONNETON CH, VINCENT-SALOMON A, DE CREMOUX P, NOS C et al. Clinical significance of 
immunocytochemical detection of tumor cells using digital microscopy in peripheral blood and bone marrow of breast cancer patients. Clin Cancer Res 2004; 10: 1392-1400. http:// dx.doi.org/10.1158/1078-0432.CCR-0102-03

[21] MUELLER V, STAHMANN N, RIETHDORF S, RAU T, ZABEL $\mathrm{T}$ et al. Circulating tumor cells in breast cancer: correlation to bone marrow micrometastases, heterogeneous response to systemic therapy and low proliferative activity. Clin Cancer Res 2005; 11: 3678-3685. http://dx.doi. org/10.1158/1078-0432.CCR-04-2469

[22] IGNATIADIS M, GEORGOULIAS V, MAVROUDIS D. Circulating tumor cells in breast cancer. Curr Opin Obstet Gynecol 2008; 20: 55-60. http://dx.doi.org/10.1097/ GCO.0b013e3282f22b2e

[23] XENIDIS N, PERRAKI M, KAFOUSI M, APOSTOLAKI S, BOLONAKI I et al. Predictive and prognostic value of peripheral blood cytokeratin-19 mRNA-positive cells detected by real-time polymerase chain reaction in node-negative breast cancer patients. J Clin Oncol 2006; 24: 3756-3762. http:// dx.doi.org/10.1200/JCO.2005.04.5948

[24] RACK B, ANDERGASSEN U, NEUGEBAUER J, SALOMEN J, HEPP P et al. The German SUCCESS C study - The first european lifestyle study on breast cancer. Breast Care 2010; 5: 395-400. http://dx.doi.org/10.1159/000322677

[25] SCHOENFELD A, KRUGER KH, GOMM J, SINNETT HD, GAZET JC et al. The detection of micrometastases in the peripheral blood and bone marrow of patients with breast cancer using immunohistochemistry and reverse transcriptase polymerase chain reaction for keratin 19. Eur J Cancer 1997; 33: 854-861. http://dx.doi.org/10.1016/S0959-8049(97)00014-2

[26] BECKER S, BECKER-PERGOLA G, BANYS M, KRAWCZYK $\mathrm{N}$, WALLWIENER D et al. Evaluation of a RT-PCR based routine screening tool for the detection of disseminated epithelial cells in the bone marrow of breast cancer patients. Breast Cancer Res Treat 2009; 117: 227-233. http://dx.doi. org/10.1007/s10549-008-0174-3

[27] FEHM T, HOFFMANN O, AKTAS B, BECKER S, SOLOMAYER EF et al. Detection and characterization of circulating tumor cells in blood of primary breast cancer patients by RTPCR and comparison to status of bone marrow disseminated cells. Breast Cancer Research 2009; 11: R59. http://dx.doi. org/10.1186/bcr2349

[28] CHAMBERS AF, GROOM AC, MACDONALD IC. Metastasis: Dissemination and growth of cancer cells in metastatic sites. Nat Rev Cancer 2002; 2: 563-572. http://dx.doi.org/10.1038/ $\underline{\operatorname{nrc} 865}$

[29] BRUGGER W, BROSS KJ, GLATT M, WEBER F, MERTELSMANN R et al. Mobilization of tumor cells and hematopoietic progenitor cells into peripheral blood of patients with solid tumors. Blood 1994; 83: 636-640.

[30] BECKER S, SOLOMAYER E, BECKER-PERGOLA G, WALLWIENER D, FEHM T. Primary systemic therapy does not eradicate disseminated tumor cells in breast cancer patients.
Breast Cancer Res Treat 2007; 106: 239-243. http://dx.doi. org/10.1007/s10549-006-9484-5

[31] PANTEL K, SCHLIMOK G, BRAUN S, KUTTER D, LINDEMANN F et al. Differential expression of proliferationassociated molecules in individual micrometastatic carcinoma cells. J Natl Cancer Inst 1993; 85: 1419-1424. http://dx.doi. org/10.1093/jnci/85.17.1419

[32] NAUMOV GN, BENDER E, ZURAKOWSKI D, KANG SY, SAMPSON D et al. A model of human tumor dormancy: an angiogenic switch from the nonangiogenic phenotype. J Natl Cancer Inst 2006; 98: 316-325. http://dx.doi.org/10.1093/ inci/dij068

[33] MARCHES R, SCHEUERMANN R, UHR J. Cancer dormancy: from mice to man. Cell Cycle 2006; 5: 1772-1778. http://dx.doi.org/10.4161/cc.5.16.2995

[34] PIERGA JY, BIDARD FC, MATHIOT C, BRAIN E, DELALOGE S ET AL. Circulating tumor cell detection predicts early metastatic relapse after neoadjuvant chemotherapy in large operable and locally advanced breast cancer in a phase II randomized trial. Clin Cancer Res 2008; 14(21): 7004-7010. http://dx.doi.org/10.1158/1078-0432.CCR-08-0030

[35] DRAGESET V, NESLAND JM, ERIKSTEIN B, SKOVLUND E, SOMMER $\mathrm{H}$ et al. Monitoring of disseminated tumor cells in bone marrow in high-risk breast cancer patients treated with high-dose chemotherapy. Int J Cancer 2006; 118: 2877-2881. http://dx.doi.org/10.1002/ijc.21709

[36] HAYES DF, CRISTOFANILLI M, BUDD GT, ELLIS MJ, STOPECK A et al. Circulating tumor cells at each follow-up time point during therapy of metastatic breast cancer patients predict progression-free and overall survival. Clin Cancer Res 2006; 12: 4218-4224. http://dx.doi.org/10.1158/1078-0432. CCR-05-2821

[37] DE GIORGI U, VALERO V, ROHREN E, DAWOOD S, UENO NT et al. Circulating tumor cells and [18F]fluorodeoxyglucose positron emission tomography/computed tomography for outcome prediction in metastatic breast cancer. J Clin Oncol 2009; 27: 3303-3311. http://dx.doi.org/10.1200/ LCO.2008.19.4423

[38] BUDD GT, CRISTOFANILLI M, ELLIS MJ, STOPECK A, BORDEN E et al. Circulating tumor cells versus imaging-predicting overall survival in metastatic breast cancer. Clin Cancer Res 2006; 12: 6403-6409. http://dx.doi. org/10.1158/1078-0432.CCR-05-1769

[39] FEHM T, BECKER S, BECKER-PERGOLA G, SOTLAR K, GEBAUER G et al. Presence of apoptotic and nonapoptotic disseminated tumor cells reflects the response to neoadjuvant systemic therapy in breast cancer. Breast Cancer Res 2006; 8: R60. http://dx.doi.org/10.1186/bcr1611

[40] RIETHDORF S, MULLER V, ZHANG L, RAU T, LOIBL S et al. Detection and HER2 expression of circulating tumor cells: prospective monitoring in breast cancer patients treated in the neoadjuvant GeparQuattro trial. Clin Cancer Res 2010; 16: 2634-2645. http://dx.doi.org/10.1158/1078-0432.CCR-09$\underline{2042}$ 